\title{
Enhanced intestinal reabsorption due to reduced metabolism of ceftriaxone
}

Tapas K Sar ${ }^{1 *}$,Indranil Samanta ${ }^{2}$,Rabindra N Hansda ${ }^{3}$, Rinku Buragohain ${ }^{1} \&$ Tapan K Manda ${ }^{\text {1a }}$

${ }^{1}$ Department of Veterinary Pharmacology and Toxicology, West Bengal University of Animal and Fishery Sciences, 37, K. B. Sarani, Belgachia, Kolkata- 700037, West Bengal, India

${ }^{2}$ Department of Veterinary Microbiology, West Bengal University of Animal and Fishery Sciences, 37, K. B. Sarani, Belgachia, Kolkata- 700037, West Bengal, India

${ }^{3}$ Department of Veterinary Pathology,West Bengal University of Animal and Fishery Sciences, 37, K. B. Sarani, Belgachia, Kolkata- 700037, West Bengal, India

a Member Secretary, Institutional Animal Ethics Committee, WBUAFS, Kolkata, India

*Corresponding author. e-mail address: tapas.sar@rediffmail.com, Mob: +919474821915 


\begin{abstract}
The polyherbal drug $\left(\right.$ Fibrosin $\left.{ }^{\circledR}\right)$ is often used as supportive therapy with intramuscular ceftriaxone injection for treatment of mastitis. A single dose of ceftriaxone at $50 \mathrm{mg} \mathrm{kg}^{-1}$ was administered intramuscularly in six healthy lactating goats and a single oral dose of Fibrosin ${ }^{\circledR}$ (1.9 gm) was given $1 \mathrm{hr}$ prior to intramuscular ceftriaxone injection to study disposition of ceftriaxone. Plasma and urine samples were collected at predetermined time schedule and ceftriaxone/ceftizoxime was extracted and analyzed by HPLC. Ceftriaxone persisted for $3 \mathrm{hr}$ in plasma of fibrosin treated healthy lactating goats. Mean $t_{1} / 2 \mathrm{~K}$ (distribution half life) following absorption phase and $\mathrm{t}_{1 / 2} \mathrm{~K}^{\prime}$ (elimination half life) following intestinal re-absorption phase were respectively, $0.091 \pm 0.01$ and $0.43 \pm 0.03 \mathrm{hr}$ with a re-absorption half life $\left(\mathrm{t}_{1 / 2} \mathrm{Ka}^{\prime}\right)$ of $0.18 \pm 0.003$ hr.Ceftriaxone at a lower concentration $\left(67.91 \pm 9.42 \mu \mathrm{g} \mathrm{ml}^{-1}\right)$ was recovered at $24 \mathrm{hr}$ post dosing from urine. This is the first report of pharmacokinetic interaction of intramuscular ceftriaxone injection and the oral polyherbal drug (which was found to be a cytochrome $\mathrm{P}_{450}$ inhibitor).
\end{abstract}

Keywords Ceftriaxone/ Cytochrome $\mathrm{P}_{450}$ inhibitor/ Intramuscular injection / Metabolism/ Reabsorption. 


\section{Introduction}

Ceftriaxone, a third generation cephalosporin, is active against a wide range of gram negative and gram positive organisms. The drug is converted in liver to a major active metabolite i.e. ceftizoxime in goat (Sar et al, 2006; Sar et al, 2008; Sar et al, 2013) and cow (Sar et al, 2010). Ceftizoxime, a broad spectrum third generation cephalosporin, is effective against a wide variety of aerobic/anaerobic gram positive and gram negative bacteria and remains highly stable in presence of $\beta$ lactamases. The previous studies by our team suggested a typical absorptionreabsorption pattern of ceftriaxone in plasma of goat following intramammary administration at $50 \mathrm{mg} \mathrm{kg}^{-1}$ with $1 \mathrm{hr}$ prior oral dosing of the polyherbal drug $\left(\right.$ Fibrosin $\left.^{\circledR)}\right)($ Sar et al, 2011) and after intramuscular administration of ceftriaxone only at $50 \mathrm{mg} \mathrm{kg}^{-1}$ (Sar et al, 2013). Reabsorption of ceftriaxone was also observed following intravenous injection of ceftriaxone at $50 \mathrm{mg} \mathrm{kg}^{-1}$ in lactating goats with $1 \mathrm{hr}$ prior oral dosing of the polyherbal drug (Fibrosin ${ }^{\circledR}$ ) for which ceftriaxone was again available from 36 to $84 \mathrm{hr}$ post dosing in plasma following its disappearance from $3 \mathrm{hr}$ post dosing (Sar et al 2006). However, reabsorption of ceftriaxone could not be observed after intravenous injection of ceftriaxone only at $50 \mathrm{mg} \mathrm{kg}^{-1}$ (Sar et al, 2006; Guerrini et al, 1983). Administration of ceftriaxone at $46 \mathrm{mg} \mathrm{kg}^{-1}$ intravenously to sheep resulted in more rapid non-renal elimination of ceftriaxone and biliary secretion of ceftriaxone into the duodenum was reported (Arvidsson et al, 1982; Stoeckel et al, 1981). But, reabsorption may also occur in intestine. Although the previous studies on intramuscular pharmacokinetics of ceftriaxone in cow calves (Soback et al,1988; Johal \&Srivastava, 1998), camel (Goudah, 2008), cat (Abarellos et al, 2007) and goat ( Ismail et al, 2005) did not reveal any absorptionreabsorption pattern but probably blood collection at frequent interval of time may show the two phases. The veterinarians frequently use ceftriaxone intramuscularly for treatment of susceptible 
bacterial infections. Fibrosin ${ }^{\circledR}$, a polyherbal drug marketed by Legend Remedies Pvt. Ltd.,Vadadora, India, is used as supportive therapy for mastitis. The polyherbal drug facilitates cleaning of udder by clearing the tissue debris and helps in down flow of milk in mastitis (leaflet of Fibrosin ${ }^{\circledR}$ ). Fibrosin ${ }^{\circledR}$ inhibited cytochrome $\mathrm{P}_{450}$ in liver of goats following single oral dosing at $1.9 \mathrm{gm}$, but intravenous ceftriaxone injection at $50 \mathrm{mg} \mathrm{kg}^{-1}$ with $1 \mathrm{hr}$ prior oral dosing of Fibrosin ${ }^{\circledR}$ caused induction of cytochrome $\mathrm{P}_{450}$ in liver of goats (Sar et al, 2006). Fibrosin ${ }^{\circledR}$ enhanced the penetration of ceftizoxime through milk-blood barrier and increased the bioavailability of ceftizoxime in milk following a single dose intramammary administration of ceftriaxone at $50 \mathrm{mg} \mathrm{kg}^{-1}$ after its metabolism in liver (Sar et al, 2011). Oral administration of Fibrosin ${ }^{\circledR}$ also could be preferred with concurrent administration of intramuscular ceftriaxone for treatment of sensitive bacterial infections except mastitis as it causes zero level milk residue of ceftizoxime (Sar et al, 2014). The polyherbal drug also returned increased milk alkaline phosphatase and catalase activity in mastitic goats to normal level and maintained normal glutathione level with significantly increased lactoperoxidase activity with $1 \mathrm{hr}$ prior oral administration to single intravenous dosing of ceftriaxone (Sar et al, 2012). The polyherbal drug also protected mammary gland from tissue damage caused by intramammary administration of ceftriaxone (Sar et al, 2015). Milk alkaline phosphatase and catalase activity and reduced glutathione level did not differ significantly between healthy and fibrosin treated goats following single intramuscular dosing of ceftriaxone without and with $1 \mathrm{hr}$ prior oral administration of Fibrosin $^{\circledR}$ (Sar et al, 2014). Disposition of ceftriaxone exhibited absorption-reabsorption pattern in healthy goats, while it was absent in carbontetrachloride treated hepatopathic and no reabsorption in uranyl nitrate treated nephropathic goats following single intramuscular and intravenous dosing and at50 $\mathrm{mg} \mathrm{kg}^{-1}$ (Sar et al, 2013). Ceftriaxone was reported to induce 
cytochrome $\mathrm{P}_{450}$ in liver and the polyherbal drug (Fibrosin ${ }^{\circledR}$ ) was found to inhibit cytochrome $\mathrm{P}_{450}$ (Sar et al, 2006). Disposition of ceftriaxone in healthy goats following single intramuscular dosing at $50 \mathrm{mg} \mathrm{kg}^{-1}$ had already been reported (Sar et al, 2013).

Therefore, the present study was aimed to evaluate disposition kinetics of ceftriaxone in presence of the polyherbal drug $\left(\right.$ Fibrosin $\left.^{\circledR}\right)$ and to observe its effect on intestinal reabsorption of ceftriaxone following single intramuscular administration of ceftriaxone with $1 \mathrm{hr}$ prior oral dosing of Fibrosin ${ }^{\circledR}$ as the polyherbal drug was found to inhibit cytochrome $\mathrm{P}_{450}$ oxidase system in liver. The study was also conducted to explore possible pharmacokinetic interactions between intramuscular ceftriaxone injection and any cytochrome $\mathrm{P}_{450}$ inhibitor drug.

\section{Results}

The recovery percentage of ceftriaxone and ceftizoxime were $81.14 \pm 4.95 \%$ and $80.37 \pm 2.30 \%$, respectively in plasma. In urine, the recovery percentage of ceftriaxone and ceftizoxime were $85.83 \pm 4.21 \%$ and $87.56 \pm 2.84 \%$, respectively. The chromatograms of standard ceftriaxone and ceftizoxime were presented in Figure 1(a) and Figure 1(b), blank plasma in Figure 2, chromatograms of ceftriaxone and ceftizoxime extracted from plasma in Figure 3(a) and Figure 3(b), standard curve of ceftriaxone and ceftizoxime in plasma in Figure 4.

The effects of Fibrosin ${ }^{\circledR}$ on liver function tests were presented in Table 1.The normal icterus index, serum bromosulfophthalein clearance (BSP), serum aspartate transaminase activity $(\mathrm{AST})$ and serum alanine transaminase activity (ALT) were $4.64^{\mathrm{NS}} \pm 0.10$ unit, $3.32^{\mathrm{NS}} \pm 0.36$ $\min , 340.00^{\mathrm{NS}} \pm 11.64 \mu \mathrm{g}$ pyruvic acid $/ \mathrm{mL} / \mathrm{h}$ and $92.00^{\mathrm{NS}} \pm 7.83 \mu \mathrm{g}$ pyruvic acid $/ \mathrm{mL} / \mathrm{h}$ respectively in healthy lactating goats which did not differ significantly on day 3 and 7 after single dose oral administration of Fibrosin ${ }^{\circledR}(1.9 \mathrm{gm})$.

Mean plasma concentration with SE of ceftriaxone in healthy lactating goats with $1 \mathrm{hr}$ pre single dose oral administration of fibrosin (1.9 $\mathrm{gm})$ after single dose intramuscular 
administration at $50 \mathrm{mg} \mathrm{kg}^{-1}$ have been incorporated in (Table 2). Ceftriaxone attained a plasma concentration of $38.50 \pm 5.34 \mu \mathrm{g} \mathrm{ml}^{-1}$ at $0.08 \mathrm{hr}$ which started to increase gradually with a peak concentration of $69.00 \pm 8.08 \mu \mathrm{g} \mathrm{ml}^{-1}$ at $0.33 \mathrm{hr}$ and declined at $0.50 \mathrm{hr}\left(19.50 \pm 5.34 \mu \mathrm{g} \mathrm{ml}^{-1}\right)$ which again started to increase from $0.66 \mathrm{hr}$ post dosing, achieved a maximum concentration of $72.50 \pm 7.21 \mu \mathrm{g} \mathrm{ml}^{-1}$ at $1 \mathrm{hr}$ and declined to a minimum concentration of $3.00 \pm 1.01 \mu \mathrm{g} \mathrm{ml}^{-1}$ at 3 hr post dosing in lactating goats treated with fibrosin.

The semilogarithmic plot of mean plasma level time profile and disposition kinetic parameters of ceftriaxone in healthy lactating goats after single dose intramuscular administration at $50 \mathrm{mg} \mathrm{kg}^{-1}$ with $1 \mathrm{hr}$ pre single dose oral administration of Fibrosin ${ }^{\circledR}$ have been presented in Fig.5 and Table 3. In healthy fibrosin treated lactating goats, the values of K and $\mathrm{t}_{1} / 2 \mathrm{~K}$ of distribution phase were $7.85 \pm 1.07 \mathrm{hr}^{-1}$ and $0.091 \pm 0.01 \mathrm{hr}$ respectively, while $\mathrm{K}^{\prime}$ and $\mathrm{t}_{1 / 2}$ $\mathrm{K}^{\prime}$ values of elimination phase were respectively $1.65 \pm 0.15 \mathrm{hr}^{-1}$ and $0.43 \pm 0.035 \mathrm{hr}$. The values of $\mathrm{Ka}$ and $\mathrm{t} 1 / 2 \mathrm{Ka}$ of absorption phase were respectively $10.75 \pm 0.80 \mathrm{hr}^{-1}$ and $0.064 \pm 0.004$ hr. But, the values of $\mathrm{Ka}^{\prime}$ and $\mathrm{t}_{1} / \mathrm{Ka}^{\prime}$ of reabsorption phase were found to be $3.86 \pm 0.10 \mathrm{hr}^{-1}$ and $0.18 \pm 0.003 \mathrm{hr}$. Mean $\mathrm{t}_{1} / \mathrm{Ka}^{\prime}$ of reabsorption phase was manifold higher compared to mean $\mathrm{t}_{1} / 2 \mathrm{Ka}$ of absorption phase indicating prolonged and enhanced reabsorption of ceftriaxone compared to its absorption. Mean AUC and $\mathrm{Vd}_{\text {area }}$ values were $247.50 \pm 24.89 \mu \mathrm{g} \mathrm{hr} \mathrm{ml}^{-1}$ and $0.13 \pm 0.003 \mathrm{~L}$ $\mathrm{kg}^{-1}$ that indicated wider distribution coverage with lesser volume of distribution.

Ceftriaxone at a concentration of $67.91 \pm 9.42 \mu \mathrm{g} \mathrm{ml}^{-1}$ was recovered at $24 \mathrm{hr}$ post dosing from urine of the lactating goats. However, neither ceftriaxone nor ceftizoxime (active metabolite of ceftriaxone) could be detected in urine at 48 and $72 \mathrm{hr}$ post dosing.

\section{Discussion}


Single dose oral administration of Fibrosin $^{\circledR}(1.9 \mathrm{gm})$ did not change Icterus index, serum bromosulphophthalein clearance (BSP), serum aspartate transaminase activity (AST) and serum alanine transaminase activity (ALT) significantly $(\mathrm{p}<0.05)$ between different days $(0,3$ and 7$)$ which indicated that Fibrosin ${ }^{\circledR}$ does not alter normal liver functions.

Plasma concentration of ceftriaxone showed an increasing - decreasing pattern followed by the same increasing- decreasing pattern again in lactating goats following single intramuscular dosing with $1 \mathrm{hr}$ prior oral administration of Fibrosin ${ }^{\circledR}$ (Table 2). Disposition of ceftriaxone exhibited shorter absoption half life $\left(\mathrm{t}_{1} / \mathrm{k}_{\mathrm{a}}=0.064+0.004 \mathrm{hr}\right)$ and distribution half life $\left(\mathrm{t}_{1 / 2} \mathrm{k}=0.091 \pm 0.01 \mathrm{hr}\right)$ compared to increased reabsorption half life $\left(\mathrm{t}_{1 / 2} \mathrm{~K}_{\mathrm{a}}^{\prime}=0.18 \pm 0.003\right.$ hr) and elimination half life $\left(\mathrm{t}_{1} / 2 \mathrm{k}^{\prime}=0.43 \pm 0.035 \mathrm{hr}\right)$ with prior oral administration of the polyherbal drug (Table 3). Hepatic clearance of ceftriaxone predominated renal clearance in goats (Sar et al, 2008). Ceftriaxone was found to be an inducer of microsomal cytochrome $\mathrm{P}_{450}$ in liver and undergoes hydrolysis to produce its active metabolite i.e. ceftizoxime through cleavage of thioether bond present in ceftriaxone (Sar et al, 2006). Furthermore, ceftrixone having a molecular weight 554.59 is liable to excrete through bile that may undergo reabsorption in the intestine resulting in its entry into the systemic circulation followed by metabolism in liver (Sar et al, 2011; Sar et al, 2013) or reabsorption again. Therefore, biphasic increased concentration of ceftriaxone after intramuscular administration in these animals may suggest enterohepatic circulation of ceftriaxone and its intestinal reabsorption in goats.

Ceftriaxone persisted for $3 \mathrm{hr}$ in plasma of lactating goats following single intramuscular dosing at $50 \mathrm{mg} \mathrm{kg}^{-1}$ with $1 \mathrm{hr}$ prior oral administration of Fibrosin ${ }^{\circledR}$ in the present study while it persisted for $2 \mathrm{hr}$ in lactating goats without the polyherbal drug (Sar et al, 2013).The $\mathrm{K}_{\mathrm{a}}($ absorption rate constant) of ceftriaxone in presence of the polyherbal drug was $10.75 \pm 0.80$ 
$\mathrm{hr}^{-1}$ (Table 3) in the present study which increased markedly compared to $\mathrm{K}_{\mathrm{a}}$ value of $8.41 \pm 0.02$ $\mathrm{hr}^{-1}$ in healthy goats without oral administration of the polyherbal $\operatorname{drug}(\operatorname{Sar}$ et al, 2013).It indicated that the polyherbal drug has increased the absorption rate of ceftriaxone from intramuscular site as well as the persistence of the drug in the body. Moreover, it can be transpired that Fibrosin ${ }^{\circledR}$, an inhibitor of cytochrome $\mathrm{P}_{450}$ oxidase system may cause lesser/negligible metabolism of ceftriaxone through this system leading to longer persistence compared to healthy goats without fibrosin administration.

Ceftriaxone persisted for $2 \mathrm{hr}$ in plasma in healthy goats following single intramuscular dosing at $50 \mathrm{mg} \mathrm{kg}^{-1}$ and showed a reabsorption half life $\left(\mathrm{t}_{1} / \mathrm{Ka}^{\prime}\right)$ of $0.09 \pm 0.005 \mathrm{hr}$ (Sar et al, 2013). But it persisted for a longer time in fibrosin treated goats which might be due to its enhanced intestinal reabsorption and impaired metabolism in liver compared to healthy goats which is also evidenced by its two fold increased half life of reabsorption $\left(\mathrm{t}_{1 / 2} \mathrm{Ka}^{\prime}=0.18 \pm 0.003\right.$ hr) (Table 3). Ceftriaxone also showed reabsorption following enterohepatic circulation in healthy goats after intramammary administration of ceftriaxone with $1 \mathrm{hr}$ prior oral dosing of Fibrosin $^{\circledR}$ (Sar et al, 2011).The drug also showed reabsorption phase in the present study with concomitant administration of the polyherbal drug. Ceftriaxone, a lipid soluble drug having molecular weight of 554.59 is expected to excrete through biliary secretion. Enterohepatic circulation of ceftriaxone may either induce cytochrome $\mathrm{P}_{450}$ enzyme of the liver (Sar et al, 2006) and subsequently being metabolized or excrete through bile as such. Enhanced reabsorption of ceftriaxone from intestine occurred in healthy lactating goats following intramuscular administration in the present study indicating lesser metabolism of ceftriaxone due to prior oral administration of the polyherbal drug. It was also evidenced by an abruptly increased reabsorption half life with prior oral administration of the polyherbal drug as it was 
reported to inhibit cytochrome $\mathrm{P}_{450}$ enzyme of the liver (Sar et al, 2006). Sar et al, 2006; could not detect reabsorption of ceftriaxone in goats following single dose intravenous administration of ceftriaxone at $50 \mathrm{mg} \mathrm{kg}^{-1}$ (a higher dose) without prior oral dosing of the polyherbal drug (Fibrosin ${ }^{\circledR}$ ) which might be due to optimum induction of cytochrome $\mathrm{P}_{450}$ in liver with subsequent rapid metabolism as a result of cent percent bioavailability .One of the functions of liver is secretion of bile which contains pigments and bile salts. Bile salts are formed in the liver from cholesterol and excreted as sodium salts of taurocholic and glycocholic acids after conjugation with taurine and glycine which help in the emulsification of fats in the intestine for absorption of fat soluble vitamins and compounds (Sastry, 1999). Ceftriaxone, being a lipid soluble drug may be absorbed in presence of bile from the intestine. Failure of bile excretion due to hepatic damage was responsible either for accumulation of drug in the liver or interference with the further absorption of ceftriaxone resulting in absence of reabsorption phase in the disposition of the drug in hepatopathic goats (Sar et al, 2013).Ceftriaxone showed major hepatic clearence in goats which was evidenced by its higher $\mathrm{Cl}_{\mathrm{H}}$ value (Sar et al, 2008) and intestinal reabsorption of ceftriaxone occurred in the present study following intramuscular administration which indicated that the polyherbal drug did not interfere with bile secretion from liver and caused enhanced excretion of ceftriaxone through bile. The $t_{1} / 2 k$ '(elimination half life) of ceftriaxone was $0.43 \pm 0.035 \mathrm{hr}$ with prior oral administration of the polyherbal drug in the present study. But it decreased drastically compared to $t_{1} / 2 k^{\prime}$ value of $0.76 \pm 0.09 \mathrm{hr}$ in healthy goats following intramuscular dosing of ceftriaxone at the same dose rate without Fibrosin ${ }^{\circledR}$ administration (Sar et al, 2013) which may be due to enhanced excretion of the drug through bile. No reabsorption phase could be observed in disposition of ceftriaxone in previous studies by other research workers in healthy animals after intramuscular administration which might be 
due to collection of blood samples at comparatively longer intervals. Blood samples from fibrosin treated lactating goats were collected at comparatively shorter intervals from our previous experience during the study (Sar et al, 2013).

Ceftizoxime could not be detected in urine of fibrosin treated healthy goats which further suggested negligible metabolism of ceftriaxone leading to non-availability of its metabolite, ceftizoxime. It is reported that ceftriaxone induces cytochrome $\mathrm{P}_{450}$ in liver and undergoes hydrolysis to form the major active metabolite i.e. ceftizoxime following single dose intravenous and intramuscular administration at $50 \mathrm{mg} \mathrm{Kg}^{-1}$ in goats which was excreted at higher concentration in urine up to $72 \mathrm{hr}$ of collection (Sar et al, 2006; Sar et al, 2013). Oral Fibrosin ${ }^{\circledR}$ administration may decrease the content of cytochrome $\mathrm{P}_{450}$ which is responsible for impaired metabolism of ceftriaxone in healthy goats resulting in non availability of its metabolite in urine. Ceftriaxone is mixed function oxidase system inducer causing more formation of its own metabolite (ceftizoxime) which is expected to excrete through urine in healthy goats. But ceftriaxone has lesser/no effect on MFO system in presence of fibrosin resulting in negligible amount of metabolite formation which might be the reason of non availability of ceftizoxime in urine of fibrosin treated goats. Ceftriaxone is inducer of hepatic microsomal enzyme systems while fibrosinis the inhibitor of the enzyme and combined therapy induced enzyme activity (Sar et al, 2006). Interestingly, combined therapy of intramuscular ceftriaxone injection and oral Fibrosin $^{\circledR}$ (polyherbal drug) in the present study showed negligible induction of MFO system resulting in non availability of its active metabolite i.e. ceftizoxime in urine. This might be due to lesser bioavailability of ceftriaxone following intramuscular administration for which the inhibition of cytochrome $\mathrm{P}_{450}$ suppressed induction of cytochrome $\mathrm{P}_{450}$ by ceftriaxone. Either ceftizoxime or ceftriaxone also could not be detected in milk following intramuscular 
administration of ceftriaxone at $50 \mathrm{mg} \mathrm{kg}^{-1}$ with $1 \mathrm{hr}$ prior oral dosing of the polyherbal drug (Sar el al, 2014).

Intramuscular administration of ceftriaxone with concomitant oral administration of Fibrosin ${ }^{\circledR}$ may be recommended particularly as persistence of the antibiotic is increased in plasma with zero level milk residue and lesser degree of elimination for shorter duration in urine that may subside public health hazard and lesser chances of development of antimicrobial resistance to both ceftriaxone and ceftizoxime.

The reabsorption of ceftriaxone following intramuscular administration even with concurrent administration of cytochrome $\mathrm{P}_{450}$ inhibitor should be taken into account for calculating therapeutic dosage regimen, drug interactions and drug monitoring in different disease conditions. Moreover, Fibrosin ${ }^{\circledR}$ (the polyherbal drug) could be used as a representative cytochrome $\mathrm{P}_{450}$ inhibitor for pharmacokinetic interaction study of ceftriaxone particularly as it did not interfere with bile secretion and liver function tests like icterus index, serum bromosulfophthalein clearance (BSP), serum aspartate transaminase activity (AST), serum alanine transaminase activity (ALT) but inhibited cytochrome $\mathrm{P}_{4500 x i d a s e}$ system in liver.

\section{Materials and Methods}

\section{Drugs and Chemicals}

Ceftriaxone (analytical grade, purity $\geq 90 \%$;Estral Pharmaceutical Industries, Vadadora, Gujarat, India) was used as test drug. Ceftizoxime (analytical grade, purity $\geq 90 \%$ ) was obtained from GlaxoSmithkline Pharmaceuticals Ltd, Nashik, India. Other chemicals were obtained from Sigma Aldrich, USA.Fibrosin ${ }^{\circledR}$ (Legend Remedies Pvt. Ltd.,Vadodara, India) is a polyherbaldrug used for concomitant therapy with antibiotics in clinical and sub-clinical mastitis. It is composed of Kanchanar-gugal (gummy substances and resins of Bauhinia variegataLinn.), Chitrak- 
mula(root of Plumbagozeylanica), Punar-navastaka(flower of Triaanthemamonogyna), Trifala(fruit of TerminaliabelericaRetz. + fruit of TerminaliachebulaRetz.+fruit of Phylanthusamblica) and Apamarga(whole plant of AchyranthesasperaLinn.). The actual composition of Fibrosin ${ }^{\circledR}$ is trade secret of Legend Remedies Pvt. Ltd., Vadadora, India. The active principles present in these plants were presented in our earlier studies (Sar et al, 2006; Sar et al, 2011). Fibrosin ${ }^{\circledR}$ was used as ctochomeP 450 inhibitor for pharmacokinetic interaction study with intramuscular ceftriaxone injection.

\section{Animals}

A total of 6 apparently healthy lactating goats weighing between $10-12 \mathrm{~kg}$ of approximately $1 \frac{1 / 2-2}{2}$ years of age were used in this experiment. The animals were caged individually in custom made metabolic cages (stainless steel) during experimental period. Artificial lighting facility was provided with 12 hour dark period. Animals were stall-fed and the standard feed as well as water was provided ad libitum.The composition of the feed was 2 parts wheat husk, 1 part groundnut cake, 1 part crushed gram, 1 part crushed maize, and 2 parts greens. The animals were dewormed with a single oral dose of rafoxanide at $7.5 \mathrm{mg} \mathrm{kg}^{-1}$ body weight 30 days prior to the onset of study. Before the start of the experiment, the animals were acclimatized for 7 days.

\section{Experimental design}

The effects of Fibrosin ${ }^{\circledR}$ in liver of six healthy lactating goats were assessed by performing icterus index, serum bromosulphophthalein clearance (BSP), serum aspartate transaminase activity (AST), serum alanine transaminase activity (ALT). For this study, a half bolus of Fibrosin ${ }^{\circledR}$ (1.9 gm) was administered orally making suspension in $50 \mathrm{ml}$ distilled water 
to each lactating goat and the tests were performed collecting serum before oral dosing of Fibrosin ${ }^{\circledR}$ and on day 3 and 7 after Fibrosin ${ }^{\circledR}$ administration.

For pharmacokinetic interaction study, a single dose of ceftriaxone dissolving in $5 \mathrm{ml}$ of distilled water was administered at $50 \mathrm{mg} \mathrm{kg}^{-1}$ body weight to each animal deep at thigh muscle. A half bolus of fibrosin (1.9 $\mathrm{gm})$ was administered orally to each goat before $1 \mathrm{hr}$ of ceftriaxone administration making suspension in $50 \mathrm{ml}$ distilled water. The same animals were utilized for pharmacokinetic interaction study after allowing a washing period of 1 month.

\section{Collection of samples}

Blood samples werecollected from jugular vein at ' 0 ' and at $0.08,0.16,0.25,0.33,0.50$, $0.66,0.83,1,2,3$ and $4 \mathrm{hr}$ post dosing of intramuscular ceftriaxone injection. Plasma was then separated and utilized for estimation of drug concentration.

Urine samples were collected at $0,24,48$ and $72 \mathrm{hr}$ post dosing for analysis of ceftriaxone/ceftizoxime.

\section{Biochemical tests}

\section{Bromosulphophthalein (BSP) clearance test}

The test was carried out in the serum of goats before administration of fibrosin ${ }^{\circledR}(1.9 \mathrm{gm})$ and on day 3 and 7 and bromosulphophthalein (BSP) clearance (Varley et al, 1975) was expressed as $\mathrm{t}_{1} / 2 \min$ (elimination half life).

\section{Icterus index}

The test was carried out in the serum of goats ${ }^{17}$ at ' 0 ' (pre dosing of fibrosin ${ }^{\circledR}$ ), day 3 and 7 following oral administration of fibrosin ${ }^{\circledR}$ and was expressed as unit.

\section{Estimation of serum AST and ALT activity}


Serum AST (aspartate aminotransferase) and ALT (alanine aminotransferase) activities were measured according to the method of Yatazidis (Yatazidis, 1960).

\section{Analysis of ceftriaxone and ceftizoxime}

Extraction of ceftriaxone as well as its metabolite, ceftizoxime from plasma and urine was done which were subsequently analyzed by HPLC. Plasma or urine $(0.5 \mathrm{ml})$ was taken in a test tube, $0.5 \mathrm{ml}$ of mobile phase was added to it. After that $2 \mathrm{ml}$ of the mixture containing $70 \%$ methanol, sodium acetate $(30 \%$ of $0.1 \mathrm{M})$ added to the test tube to make a total volume of $3 \mathrm{ml}$ and $\mathrm{pH}$ (5.2) was adjusted by using HPLC grade acetic acid (1-2 drops). The mixture was vortexed for 30 minute and incubated at $4^{0} \mathrm{C}$ for $15 \mathrm{~min}$. The whole aliquot was centrifuged at $3000 \mathrm{rpm}$ for $15 \mathrm{~min}$. and supernatant was collected after passing through a filter paper (Whatman No. 1 Rankem).The supernatant $(20 \mu \mathrm{l})$ was analysed by SHIMADZU LC-20AT liquid chromatogram coupled with Photo Diode-Array detector (UV-VIS) attached with

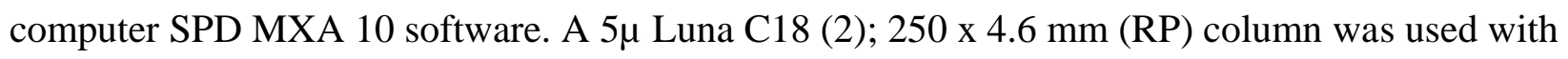
the flow rate of $1.0 \mathrm{ml} / \mathrm{min}$ and $254 \mathrm{~nm}$ wavelength. The mobile phase was prepared according to the method of USP (United States Pharmacopoeia) for analysis of ceftriaxone. Standard and sample $(20 \mu 1)$ were injected into the injector port of liquid chromatography with the first and last being the standard. The drugs were estimated after comparing with external standard. Calibration was done every time by a standard stock solution of $20 \mathrm{ppm}$ of the test drugs of analytical grade prepared in distilled water. Recovery of ceftriaxone/ceftizoxime from plasma and urine was carried out in vitro by adding known quantities of ceftriaxone/ceftizoxime to give final concentrations of $0.005,0.01,0.05,0.1,0.25,0.50,1,2,5,10$ and $20 \mu \mathrm{g} \mathrm{ml}^{-1}$. The limit of detection for both the drugs was $0.01 \mu \mathrm{g} \mathrm{ml}^{-1}$. The retention times of ceftriaxone and ceftizoxime were 9.549 and 4.504, respectively which showed inter-day variations.

\section{Pharmacokinetic analysis}


The concentration of ceftriaxone in plasma of lactating healthy goats at different time intervals was plotted on a semilogarithmic paper and the pharmacokinetic parameters were analysed by non-compartmental method. The initial increased concentration was considered as absorption phase $\left(\mathrm{K}_{\mathrm{a}}\right)$ which was followed by decreased concentration and considered as distribution phase $(\mathrm{K})$. The concentration increased again considered as reabsorption phase $\left(\mathrm{K}_{\mathbf{a}}^{\prime}\right)$ followed by decreased concentration considered as elimination phase ( $\left.\mathrm{K}^{\prime}\right)$. All these half-lives were calculated from the same graph and AUC (area under curve) was determined based on trapezoid method. The other pharmacokinetic parameters were determined as per the method of Baggot (Baggot, 1977). The pharmacokinetic parameters such as $K, K^{\prime}, K_{a}, K_{a}^{\prime}$ are indicated for $\mathrm{K}$ distribution rate constant, $\mathrm{K}^{\prime}$ elimination rate constant, $\mathrm{K}_{\mathrm{a}}$ absorption rate constant, $\mathrm{K}^{\prime} \mathrm{a}$ reabsorption rate constant in healthy lactating goats in which pharmacokinetic profile of ceftriaxone showed a distinct reabsorption phase.

\section{Statistical analysis}

The results were expressed as Mean \pm Standard error (S.E.). The data were analyzed statistically using general linear model with univariate data in SPSS 10.0 version of software (students's t test).

\section{Acknowledgements}

The authors provide sincere gratitude to the honourable Vice Chancellor, West Bengal University of Animal and Fishery Sciences for necessary facilities and infrastructure. The authors are thankful to Dr. Amlan Kumar Patra, Department of Animal Nutrition, WBUAFS for statistical analysis and editing the manuscript.

\section{Author Contributions}


TKS conducted the experiment, IS and RNH wrote and edited the manuscript, RB helped to modify estimation method, TKM designed the experiment

\section{Conflict of interest}

The authors declare that they have no conflict of interest.

\section{Compliance with Ethical Standards}

No external fund was received by any of the author for the work. The authors would like to disclose no potential conflicts of interests. All applicable institutional guidelines for the care and use of animals were followed.

\section{References}

Abarellos GA, Kreil VE, Landoni MF (2007) Pharmacokinetics of ceftriaxone after intravenous, intramuscular and subcutaneous administration to domestic cats.J Vet PharmacolThera 30: 345-352

Arvidsson A, Alván G, Angelin B, Borgå O, Nord CE (1982) Ceftriaxone: renal and biliary excretion and effect on the colon microflora. J AntimicrobChemother 10: 207-215

Baggot JD (1977) Principles of drug disposition in domestic animals. In The basic of veterinary clinical pharmacology, WB Saunders Co., Philadelphia

Goudah A (2008) Pharmacokinetic parameters of ceftriaxone after single intravenous and intramuscular administration in camels (Camelus dromedaries).Res Vet Sci 84: 483- 489

Guerrini VH, Fillipich LJ, Cao GR, English PB, Bourne DW (1983) Pharmacokinetics of cefaronide, ceftriaxone and cefoperazone in sheep. $J$ Vet PharmacolThera 8: 120-127

Ismail MM (2005) Pharmacokinetics, urinary and mammary excretion of ceftriaxone in lactating goat.J Vet Med A 52: 354-358 
Johal B and Srivastava AK (1998) Pharmacokinetics, urinary excretion and dosage regimen of ceftriaxone in crossbred cow calves following single intramuscular administration. Indian J AnimSci 68: 1017-1019

Sar TK, Mandal TK, Das SK, Chakraborty AK (2008) Pharmacokinetics of ceftriaxone in carbon tetrachloride-induced hepatopathic and uranyl nitrate-induced nephropathic goats following single dose intravenous administration.Drug Met Lett2: 23-28

Sar TK, Mandal TK, Das SK, Chakraborty AK, Bhattacharyya A (2006) Pharmacokinetics of ceftriaxone in healthy and mastitic goats with special reference to its interaction with polyherbal drug (Fibrosin®).Int J Appl Res Vet Med 4: 142-154

Sar TK, Mandal TK, Patra PH, Samanta I (2013)Disposition of ceftriaxone in hepatopathic goats following single-intramuscular dosing.European J Drug Met Pharma38: 269-273

Sar TK, Mandal TK, Samanta I, Rahaman A, Chakraborty AK (2010) Determination of ceftriaxone in plasma and ceftizoxime in milk of mastitic cows following single dose intravenous administration. Indian J AnimSci 80: 182-184

Sar TK, Mandal TK, Samnta I (2014) Milk level of ceftizoxime following single intramuscular dosing of ceftriaxone without and with oral administration of Fibrosin ${ }^{\circledR}$ and its effect on milk enzyme activity in goat. ExplorAnim Med Res4:188-193

Sar TK, Patra AK, Samanta I, Mandal TK (2015) Protective effect of a potential polyherbal drug on mammary tissue damage caused by intramammary administration of antibiotic by producing antioxidant action.Indian J AnimHlth 54: 35-42

Sar TK, Patra PH, Dash JR, Mandal TK (2011) Pharmacokinetic interaction of intramammary ceftriaxone and oral polyherbal drug (Fibrosin®) in goats. Drug Met Drug Interact 26: $191-196$ 
Sar TK, Samanta I, Patra PH, Mandal TK (2012) Effect of combined therapy of intravenous ceftriaxone and oral polyherbal drug on milk enzyme activity in healthy and mastitic goats.Appl Bio Res 14:95-99

Sastry GA (1999) Veterinary Pathology. $7^{\text {th }}$ edn., CBS Publishers, India.

Soback W and Ziv G (1988) Pharmacokinetics and bioavailability of ceftriaxone administered intravenous and intramuscularly to calves.Am J Vet Res 49: 535-538

Stoeckel K, McNamara PJ, Brandt R, Plozza-Nottebrock H, Ziegler WH (1981) The effects of concentration-dependent plasma protein bindings on the pharmacokinetics of ceftriaxone (RO 13-9904), a new parenteral cyphalosporin. ClinPharmacolTher 29: 650 -657

Varley H (1975) In Practical Clinical Bio-chemistry, Amold-Heinemann Publishers (India) Pvt. Ltd., New Delhi

Yatazidis H (1960) Measurement of transaminase in serum. Nature 18: 79-80 
Table 1 Mean values with SE of icterus index, serum bromosulfophthalein clearance (BSP), serum aspartate transaminase activity (AST), serum alanine transaminase activity (ALT) in healthy lactating goats following single dose oral administration of fibrosin ${ }^{\circledR}(1.9 \mathrm{gm})$.

\begin{tabular}{|c|c|c|c|c|}
\hline Day & Icterus index (unit) & BSP Clearance $\left(t_{1 / 2}\right.$ min $)$ & AST activity $(\mu \mathrm{g}$ & ALT activity \\
\hline & & & pyruvic & pyruvic \\
\hline & & & acid/mL/h) & $\operatorname{acid} / \mathbf{m L} / \mathbf{h})$ \\
\hline 0 & $4.64^{\mathrm{NS}} \pm 0.10$ & $3.32^{\mathrm{NS}} \pm 0.36$ & $340.00^{\mathrm{NS}} \pm 11.64$ & $92.00^{\mathrm{NS}} \pm 7.83$ \\
\hline 3 & $4.61^{\mathrm{NS}} \pm 0.09$ & $3.05^{\mathrm{NS}} \pm 0.15$ & $340.00^{\mathrm{NS}} \pm 11.67$ & $85.33^{\mathrm{NS}} \pm 7.73$ \\
\hline 7 & $4.30^{\mathrm{NS}} \pm 0.07$ & $3.07^{\mathrm{NS}} \pm 0.11$ & $331.67^{\mathrm{NS}} \pm 7.88$ & $83.33^{\mathrm{NS}} \pm 6.68$ \\
\hline
\end{tabular}

Means present in each column do not differ significantly 
Table 2 Mean plasma concentration $\left(\mu \mathrm{g} \mathrm{ml}^{-1}\right)$ of ceftriaxone in healthy lactating goats without and with $1 \mathrm{hr}$ pre single dose oral administration of fibrosin (1.9 gm) after single dose intramuscular administration at $50 \mathrm{mg} \mathrm{kg}^{-1}$

\section{Time (hr)}

0.08

0.16

0.25

0.33

0.50

0.66

0.83

1

2

3

4
Fibrosin treated healthy lactating goats

$38.50^{\text {bcd }} \pm 5.34$

$46.90^{\text {cdef }_{ \pm}} 6.40$

$56.00^{\text {def }_{ \pm}} 6.92$

$69.00^{\mathbf{e f}_{ \pm}}+8.08$

$19.50^{\mathrm{abc}} \pm 5.34$

$29.80^{\text {abcd }_{ \pm}} 6.37$

$45.66^{\text {bcde }} \pm 7.41$

$72.50^{\mathbf{f}} \pm 7.21$

$14.90^{\mathrm{ab}} \pm 3.69$

$3.00^{\mathrm{a}} \pm 1.01$

BDL

BDL - Below detection limit; Means bearing a common superscript do not differ significantly $(\mathrm{p}<0.05)$ 
Table 3 Mean kinetic parameter of ceftriaxone in healthy lactating goats without and with $1 \mathrm{hr}$ pre single dose oral administration of fibrosin (1.9 gm) after single dose intramuscular administration at $50 \mathrm{mg} \mathrm{kg}^{-1}$

$\begin{array}{cc}\text { Kinetic parameters } & \text { Fibrosin treated healthy lacta } \\ \mathrm{K}_{\mathrm{a}}\left(\mathrm{hr}^{-1}\right) & 10.75 \pm 0.80 \\ \mathrm{t}_{1 / 2} \mathrm{~K}_{\mathrm{a}}(\mathrm{hr}) & 0.064+0.004 \\ \mathrm{~K}\left(\mathrm{hr}^{-1}\right) & 7.85 \pm 1.07 \\ \mathrm{t}_{1 / 2} \mathrm{~K}(\mathrm{hr}) & 0.091 \pm 0.01 \\ \mathrm{~K}_{\mathrm{a}}^{\prime}\left(\mathrm{hr}^{-1}\right) & 3.86 \pm 0.10 \\ \mathrm{t}_{1 / 2} \mathrm{~K}_{\mathrm{a}}^{\prime}(\mathrm{hr}) & 0.18 \pm 0.003 \\ \mathrm{~K}^{\prime}\left(\mathrm{hr}^{-1}\right) & 1.65 \pm 0.15 \\ \mathrm{t}_{1 / 2} \mathrm{~K}^{\prime}(\mathrm{hr}) & 0.43 \pm 0.035 \\ \mathrm{Vd}_{\mathrm{area}}\left(\mathrm{L} \mathrm{kg}{ }^{-1}\right) & 0.13 \pm 0.003 \\ \left.\mathrm{ml}^{-1}\right)[\mathrm{Based} \text { on trapizoid method] } & 247.50 \pm 24.89\end{array}$

AUC $\left(\mu \mathrm{g} \mathrm{hr} \mathrm{ml}^{-1}\right)$ [Based on trapizoid method]

$247.50 \pm 24.89$

$K_{a}$ absorption rate constant, $t_{1 / 2} K_{a}$ absorption half-life, $K$ distribution rate constant, $t_{1} / 2$ distribution halflife, $\mathrm{K}_{\mathrm{a}}^{\prime}$ re-absorption rate constant, $\mathrm{t}_{1 / 2} \mathrm{~K}_{\mathrm{a}}$ re-absoption half-life, $\mathrm{K}^{\prime}$ elimination rate constant, $\mathrm{t}_{1 / 2} \mathrm{~K}^{\prime}$ elimination half-life, $\mathrm{Vd}_{\text {area }}$ apparent volume of distribution, $\mathrm{AUC}$ total area under the plasma ceftriaxone concentration vs. time curve. 
Table 4:Mean urine concentration $\left(\mu \mathrm{g} \mathrm{ml} \mathrm{m}^{-1}\right)$ of ceftizoxime (metabolite of ceftriaxone) and ceftriaxone in healthy lactating goats without and with $1 \mathrm{hr}$ pre single dose oral administration of fibrosin (1.9 gm) after single dose intramuscular administration of ceftriaxone at $50 \mathrm{mg} \mathrm{kg}^{-1}$

\section{Fibrosin treated healthy lactating}

Time (hr)

$\begin{array}{ccc} & \text { Ceftriaxone } & \text { Ceftizoxime } \\ 0-24 & 67.91 \pm 9.42 & \text { BDL } \\ 24-48 & \text { BDL } & \text { BDL } \\ 48-72 & \text { BDL } & \text { BDL }\end{array}$

BDL - Below detectable level

\section{Figure legends}

Fig. 1(a) Chromatogram of ceftriaxone (10 ppm); RT = 9.549

Fig. 1(b) Ceftizoxime (10 ppm); RT = 4.504

Fig.2 Chromatogram of blank plasma

Fig. 3(a) Chromatogram of ceftriaxone extracted from plasma

Fig. 3(b) Chromatogram of ceftizoxime extracted from plasma (in-vitro)

Fig.4 Standard curve of recovery of ceftriaxone (a) and ceftizoxime (b) in plasma

Fig.5Semilogarithmic plot of mean plasma concentration $(\mu \mathrm{g} / \mathrm{ml})$ of ceftriaxone in lactating goats after single-dose intramuscularadministration of ceftriaxone at $50 \mathrm{mg} / \mathrm{kg}$ with $1 \mathrm{hr}$ pre single dose oral administration of Fibrosin ${ }^{\circledR}$ [X-axis: time (hr), Y-axis: plasma concentration of ceftriaxone $\left.\left(\mu \mathrm{gm} \mathrm{ml}^{-1}\right)\right]$. 


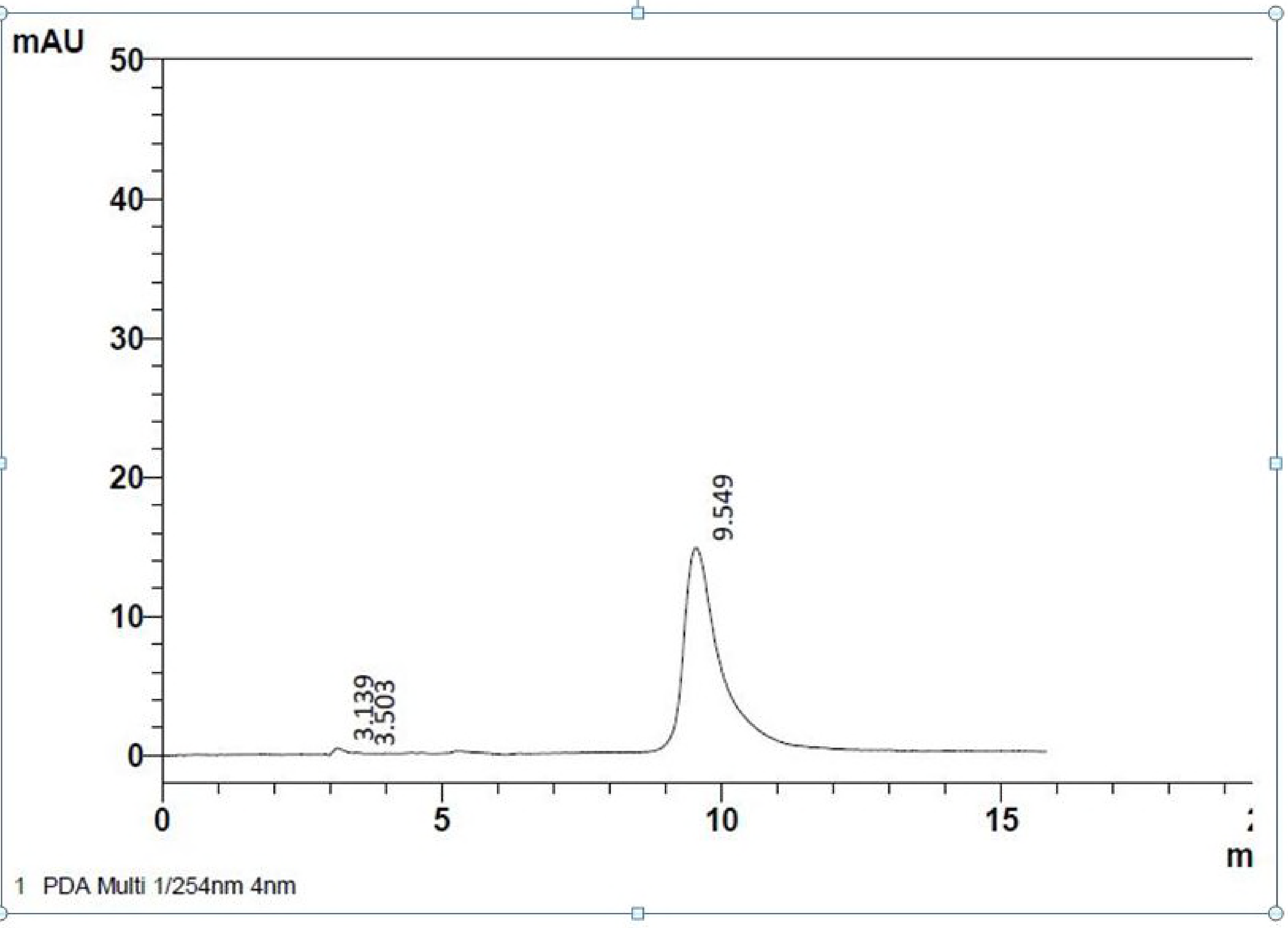




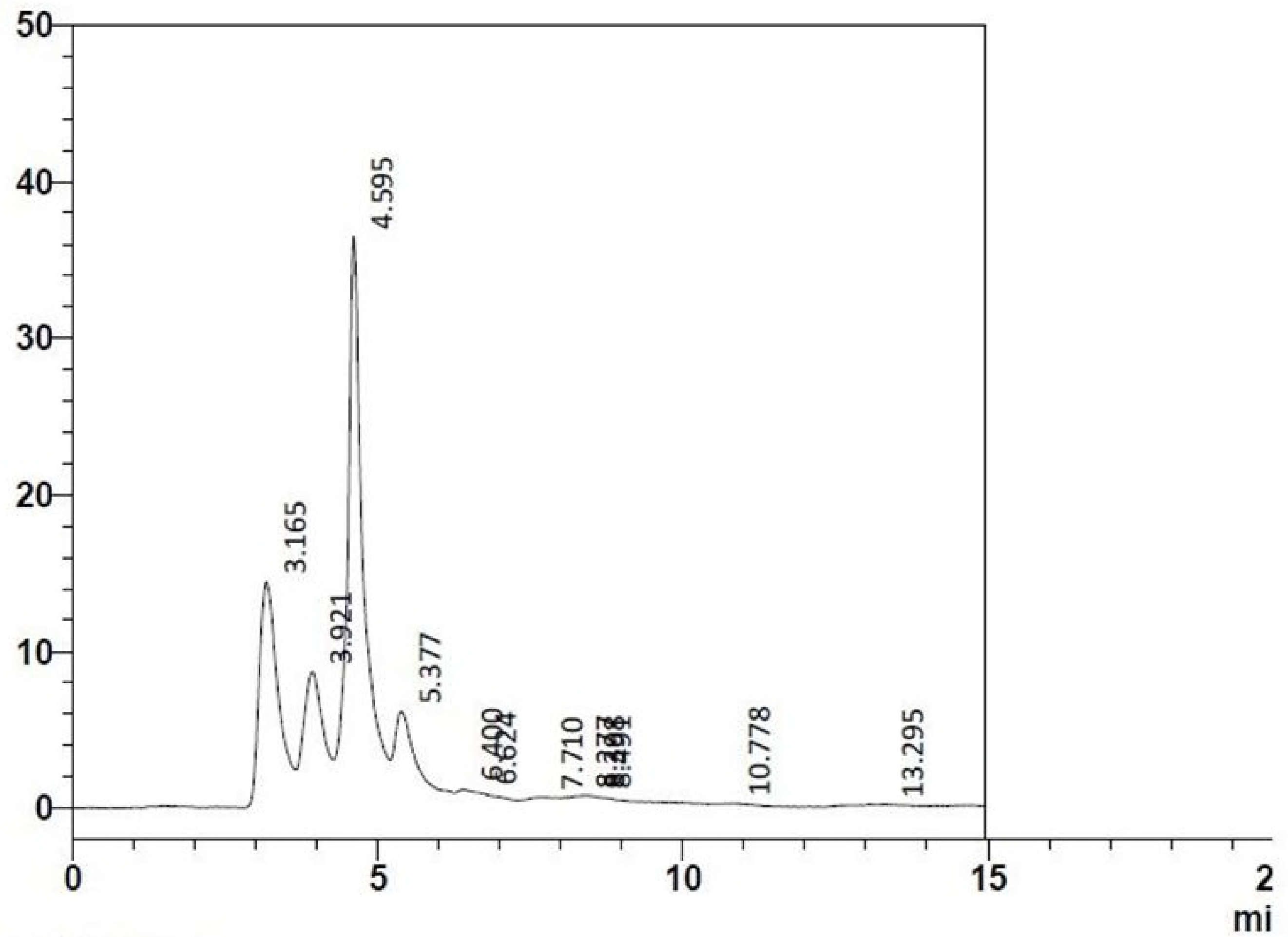




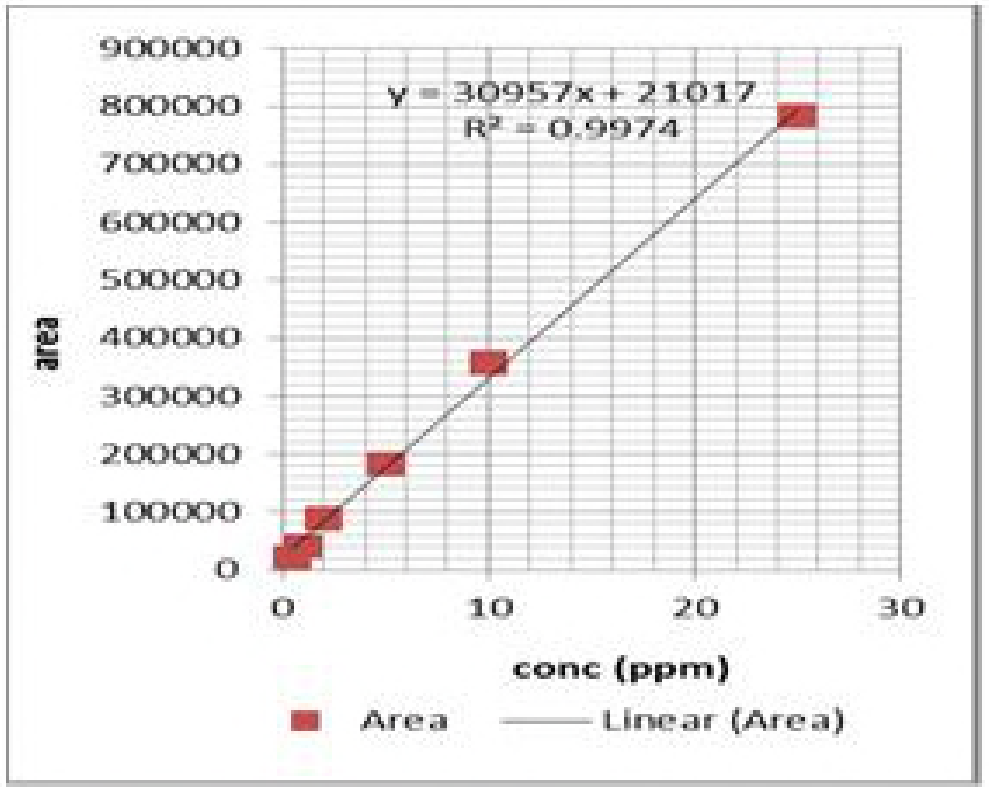




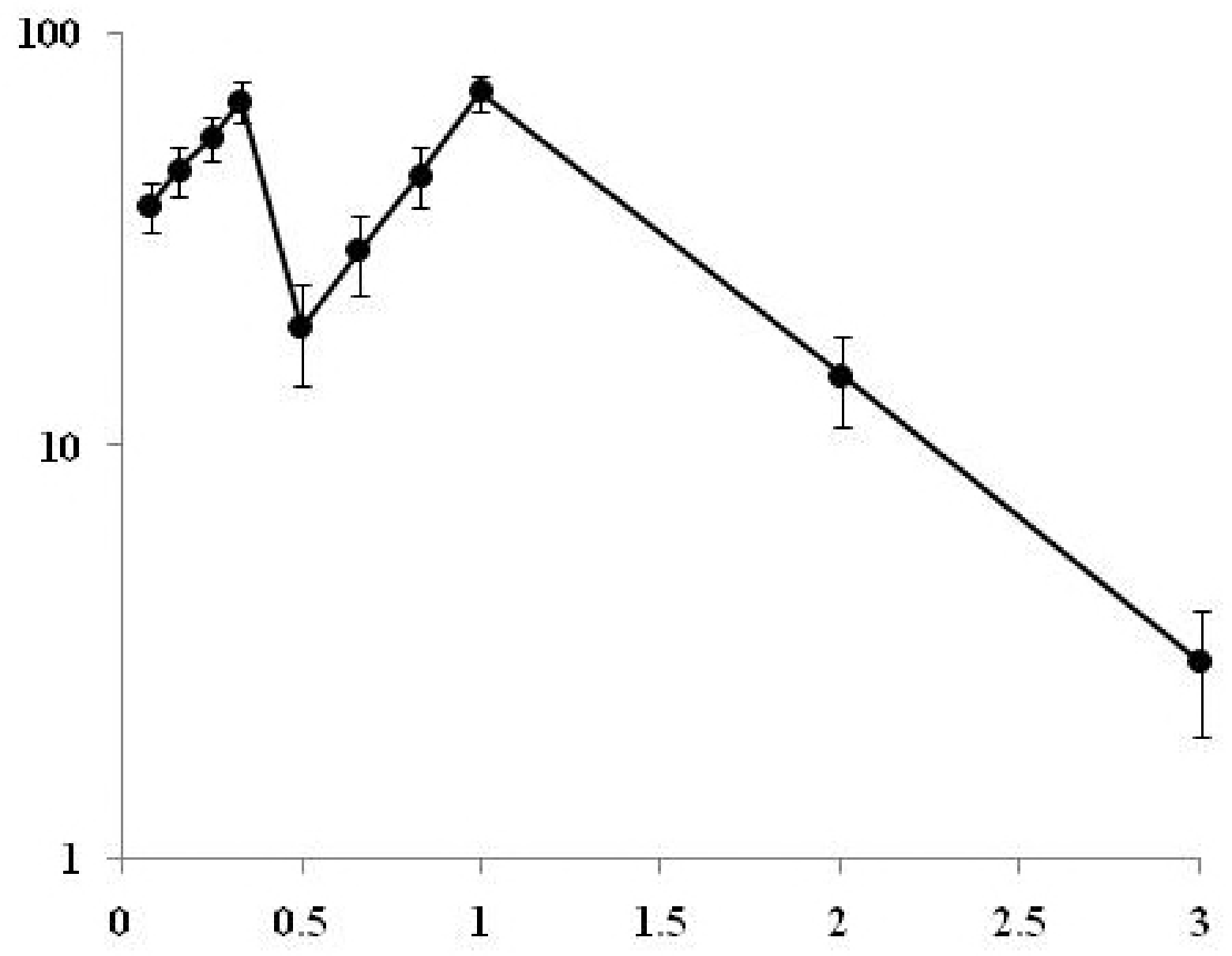

